\title{
Effect of locally delivered $0.2 \%$ Thymoquinone gel in subjects with Grade C Periodontitis: Clinical, Immunological and Microbiological Assessment
}

Author: Walid Elamrousy, Department of Periodontology, Faculty of Dentistry, Kafrelsheikh University, Kafrelsheikh, Egypt Email: waled_hammed@den.kfs.edu.eg Tel: +201005724781

\begin{abstract}
:
Objectives:

To evaluate the clinical, immunological and microbiological efficacy of local application of Thymoquinone $(T Q)$ gel in subjects with grade $C$ periodontitis.

Materials and Methods:

Twenty-six individuals of both sexes aged between 24 and 37 years, diagnosed as grade $C$ periodontitis with pocket depth $\geq 5 \mathrm{~mm}$ were selected for this study. The patients received a complete prophylaxis including scaling and root planning (SRP) followed by local intrapocket administration of placebo gel in the control group and $0.2 \% \mathrm{TQ}$ gel in the study group sites. Probing pocket depth (PPD), relative attachment level (RAL), matrix metallo-proteniease-8 (MMP8) concentration in gingival crevicular fluid (GCF) and Aggregatibacter actinomycetecomitans (A.a) count in subgingival plaque were measured and recorded at baseline and 8 weeks postoperatively.

Results:

At 8 weeks evaluation period, TQ group showed a significant reduction in PPD, RAL, MMP-8 levels in GCF and A.a count in subgingival plaque samples when compared to the placebo group.

Conclusion:
\end{abstract}

The results showed more favorable clinical, immunological and microbiological outcomes with topically administered $0.2 \% \mathrm{TQ}$ gel when used as an adjunct to nonsurgical periodontal therapy in subjects with grade $C$ periodontitis.

Keywords: Thymoquinone, local drug delivery, grade $C$ periodontitis, Nigella sativa

Introduction:

According to the current classification of periodontal diseases Aggressive periodontitis is named periodontitis grade $\mathrm{C}^{(1)}$. The prevalence of Aggressive periodontitis ranged from 0.3 to $4.5 \%$ of population, with the localized form being less prevalent ${ }^{(2)}$. Localized grade $\mathrm{C}$ periodontitis occurs mainly in teenagers with high risk of tooth loss at young age due to rapid progressive destruction of periodontal tissue and rapid alveolar bone resorption. It mainly occurs in the incisors and first permanent molars, and is generally symmetrically distributed. In addition, it can affect the adjacent teeth if not early treated properly ${ }^{(3)}$.

Oral hygiene instructions and SRP are performed to reduce and eliminate the dental biofilm, and consequently, the pathogenic microbiota responsible for localized grade 
ISSN 2515-8260 Volume 05, Issue 01, 2018

C periodontitis. Unfortunately, SRP cannot access for deeper pockets, furcation areas and root concavities ${ }^{(4)}$. Besides that, SRP is not able to remove all embedded microbial pathogens into the dentinal tubules, leading to recolonization of bacterial to the root surface and consequently recurrence of localized grade $\mathrm{C}$ periodontitis after treatment $^{(5)}$.

The European Federation of Periodontology Workshop on the Clinical Guidelines did not recommend the use of systemic chemotherapeutic agents in the clinical routine for the treatment of Periodontitis stages $\mathrm{I}-\mathrm{III}^{(6)}$. Thus, evidence-based clinical guidelines suggested that local drug delivery as adjunct to subgingival instrumentation could be preferred because of the drug release at the site of action, the ease of controlling its concentration, the reduced adverse effects and the absence of bacterial resistance detected upon using systemic antibiotics ${ }^{(7)}$.

Herbal medicine has gained researchers' attention for the treatment of oral and periodontal diseases due to its beneficial, safer, integrated effects, reduced cost and minimal side effects ${ }^{(8)}$. Nigella sativa (NS) is known as "black seed", a flowering plant that grows in Middle East, some Asian and Mediterranean countries. Furthermore, NS was shown to have no severe side effects or toxicological effects in human and animal models ${ }^{(9,10)}$.

TQ is one of the main bioactive components of NS, it has valuable therapeutic effect because of its anti-oxidant, antimicrobial, analgesic, anti-inflammatory, antihypertensive, anti-histaminic, hypoglycemic, hepatoprotective, anticarcinogenic, and immune-activating properties ${ }^{(11)}$.

Considering the anti-inflammatory, antimicrobial and antioxidant characteristics of $\mathrm{TQ}$, it may play a significant role in preventing the initiation, progression and treatment of periodontal diseases ${ }^{(12)}$. Few clinical trials have been performed to prove

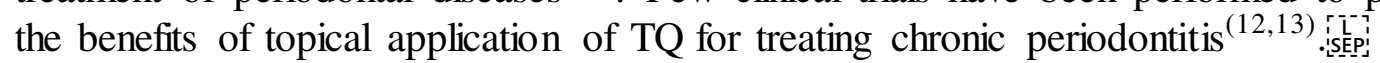

To the best of our knowledge, this is the first study that will evaluate the topical effect of TQ as an adjunctive to SRP for treating localised periodontitis grade C.

However, there is no information on whether the use of TQ topically in adjunction with non-surgical periodontal therapy could be effective in localised periodontitis grade $\mathrm{C}$ cases. Therefore, the aim of this study was to find out whether local TQ delivery would be efficient to act as an adjunct to SRP to improve the periodontal clinical parameters in patients with localised periodontitis grade $\mathrm{C}$.

\section{Materials and Methods \\ Source of Data}

The patients for this study were selected from the outpatient clinics of the Department of Oral medicine and Periodontology, Faculty of Dentistry, Kafrelsheikh University, Egypt, from October 2016 to June 2017. A total of 26 patients aged 24 to 37 years (15 men and 11 women) who were diagnosed as localized stage III/IV grade C periodontitis were enrolled in this study (Fig.1). It was clearly explained to the potential patients that participation in this study was voluntary. Written informed consent was obtained from each patient.

\section{Selection Criteria}

Based on the alveolar bone loss patterns, in relation to the periodontitis classification $\operatorname{system}\left({ }^{14)}\right.$, all patients included in this study were classified as localized stage III/IV grade C periodontitis with probing depth $\geq 5 \mathrm{~mm}$, systemically healthy individuals with no history of periodontal therapy or systemic antibiotic therapy in the last 6 months. Individuals with known systemic disease; immunodeficiency disease, allergy to any material used in the present study; periodontitis other than 
ISSN 2515-8260 Volume 05, Issue 01, 2018

localized stage III/IV grade C periodontitis; pregnant females; current and former smokers; users of any form smokeless tobacco and alcoholics were excluded from the study.

26 subjects, who matched the inclusion and exclusion criteria, were recruited for double blind clinical study. Random assignment of the involved sites was performed by computer generated system to either TQ (30 sites) or placebo group (30 sites). Another clinician implemented the treatment protocol to the two groups. An examiner, who was masked to the treatment protocol applied to the subjects, recorded all pre- and post-treatment clinical parameters.

SRP was performed by the same operator at baseline until the root surface becomes smooth and clean. In the TQ group, sites were treated with SRP followed by $0.2 \%$ TQ topical (intra-pocket) gel, while in the placebo group sites were treated with SRP followed by placebo topical (intra-pocket) gel.

\section{Intra-examiner calibration}

For intra-examiner calibration, 30 sites were examined twice. Calibrations were considered for measurements similar to $1 \mathrm{~mm}$ at the $95 \%$ level.

Formulation of $0.2 \% \mathrm{TQ}$ gel

Using a mortar and pestle, crystal form of $99 \%$ pure TQ extract (Xian Nahanutri Biotech Co., Ltd. China) was converted to powder. Then 14 gm of carbopol was mixed with $485 \mathrm{ml}$ of hot water heated at $80-90{ }^{\circ} \mathrm{C}$ and the mixture was stirred for 30 min. Add $1 \mathrm{gm}$ of TQ to the mixture to get a $0.2 \%$ concentration of TQ and continue stirring till obtaining homogenous mix. The $\mathrm{pH}$ of the gel was adjusted to 7.0 using 1 $\mathrm{N}$ Sodium hydroxide. The mixture was cooled at the room temperature $\left(35^{\circ} \mathrm{C}\right)$.

Drug release from $0.2 \%$ TQ gel after 8 hours was found to be $95.01 \pm 1.26$ by using $253 \mathrm{~nm}$ Ultra Violet-visible spectrophotometer analysis.

\section{Local drug delivery}

The prepared $0.2 \%$ TQ gel for the study group and the placebo gel for the control group was dispensed slowly using a syringe with a blunt cannula into the base of the periodontal pockets of the selected sites till the pockets were overfilled. Patients were instructed not to drink, eat, brush or rinse for an hour, and not to use interdental cleansing aids at the treated sites and to avoid chewing sticky or hard food until the end of the study (Fig. 3).

This procedure was repeated every week starting from baseline up to 4 weeks.

\section{Gingival crevicular fluid collection}

The selected sites were isolated using cotton rolls and were dried with a gentle air stream. Samples of GCF were collected by placing calibrated microcapillary tubes at gingival margin and were held in the same position until $5 \mu \mathrm{l}$ of the GCF was collected. The collected GCF was immediately transferred to a sterilized microcentrifuge (Eppendorff) tubes that contained $45 \mu \mathrm{l}$ of phosphate buffered saline. Then the samples were frozen at $-20 \mathrm{C}$ for quantitative measurement of MMP8 concentration in the GCF using Enzyme-Linked Immuno-Sorbent Assay (ELISA).

\section{Collection of plaque samples:}

The selected sites were dried and isolated using sterile cotton rolls, and then a sterile curette was inserted subgingivally for 10 seconds. The collected subgingival plaque samples were transferred immediately into $200 \mu$ l of phosphate buffered saline for microbiological assessment for detecting A.a by Reverse Transcription Polymerase Chain Raction (RT-PCR).

\section{Evaluation of parameters}

Measurements of PPD and RAL at baseline and at 8 weeks postoperatively were recorded using UNC-15 probe and occlusal stent respectively ${ }^{(15)}$ (Fig.2 and Fig.4). All 
ISSN 2515-8260 Volume 05, Issue 01, 2018

GCF samples were collected in the forenoon (between 10 and 11 AM) to allow for the circadian variation seen in GCF volume ${ }^{(16)}$.

Additionally an in vitro quantitative measurement of MMP-8 concentration in the GCF and assessment of the strains of $\mathrm{Aa}$ in the subgingival plaque samples, using ELISA and RT-PCR respectively, under the guidance of an expert microbiologist at baseline and at 8 weeks postoperatively ${ }^{(17)}$.

Statistical analysis

Power analysis calculations were performed before starting the study. 30 sites in each group were required to achieve $90 \%$ power and detect mean differences of the clinical parameters between groups. For intra-group comparison 'Wilcoxon Signed Rank Test' was performed and non-parametric analysis of clinical parameters. 'Independent t-test' was performed for intra-group and inter-group comparison for changes in MMP8 levels in GCF, A.a in plaque sample and for comparison of inter-group variations in clinical parameters. Statistical was performed with SPSS version 15, SPSS Inc., Chicago, IL, USA.

\section{Results}

The clinical findings obtained from the tested sites in the present study at base line and 8 weeks postoperatively were used to compare PPD and RAL of both groups (Graph 1). Throughout the study period, no inflammatory adverse reactions or complications were observed secondary to $0.2 \%$ TQ gel delivery. There was a statistical significant reduction in PPD and gain in RAL in both groups at 8 weeks when compared to baseline (Table 1 and 2).

Postoperative clinical measurements at 8 weeks after gel application revealed a substantial reduction in the PPD values. The mean PPD at baseline was $6.30 \pm 0.91$ $\mathrm{mm}$ and $6.23 \pm 0.93 \mathrm{~mm}$ in placebo group and TQ group respectively, and significantly reduced after 8 weeks to $4.30 \pm 0.91$ and $2.97 \pm 0.61 \mathrm{~mm}$ for placebo and TQ groups respectively as $P=0.00<0.05$ (Table 1 and Graph 1 ).

8 weeks postoperatively, the mean reduction of PPD measurements group was $2 \pm 0.0$ $\mathrm{mm}, 3.27 \pm 0.74 \mathrm{~mm}$ in the control and the study groups respectively. Upon comparing the two groups, the study group demonstrated statistically significant reduction of PPD values when compared to control group values 8 weeks after gel application as $P=0.00<0.05$.

The results of our study revealed that the mean RAL in the control group was found to be reduced from $8.60 \pm 0.930 \mathrm{~mm}$ a baseline to $6.57 \pm 0.97 \mathrm{~mm}$ after 8 weeks, while in the study group it was found to be reduced from $8.57 \pm 1.00 \mathrm{~mm}$ at baseline to $4.40 \pm 0.96 \mathrm{~mm}$ after 8 weeks. The mean RAL in both groups showed statistical significant reduction at 8 weeks when compared to baseline levels as $P=0.00<0.05$. The mean gain of RAL 8 weeks after gel application was $2.03 \pm 0.18 \mathrm{~mm}, 4.17 \pm 0.64$ $\mathrm{mm}$ for the control and study groups respectively as $P=0.00<0.05$. Upon comparing both groups, the RAL gain of study group was significantly higher than that of the control group as $P=0.00<0.05$ (Table 2 and Graph 1).

Immunological results using ELISA test for GCF samples demonstrated significant decrease in MMP-8 levels for the control group from $0.98 \pm 0.26$ at baseline to $0.83 \pm$ 0.20 at 8 weeks after gel application, in addition the levels of MMP-8 for the study group was improved from base line measurement $1.06 \pm 0.30$ to 8 weeks measurements $0.72 \pm 0.25$. Upon comparing the reduction of MMP- 8 of both groups 8 weeks after intra-pocket gel placement, there was statistical significant reduction of MMP-8 levels in the TQ group when compared to placebo group (Table 3 and Graph 2). 
ISSN 2515-8260 Volume 05, Issue 01, 2018

Regarding the Microbiological effect of TQ Using Rt-PCR index, the results of our study showed significant reduction in count of A.a in the collected subgingival plaque samples of the control group from $1.29 \pm 0.03$ to $1.17 \pm 0.20$ at base line and 8 weeks follow up period repectively. Moreover, the study group levels of A.a in the collected subgingival plaque samples were reduced from $1.30 \pm 0.19$ at baseline to $0.98 \pm 0.19$ after 8 weeks. Upon comparing the two groups, the A.a reduction level in the collected subgingival plaque samples at 8 weeks from baseline was $0.11 \pm 0.03$ for the control placebo group and $0.32 \pm 0.04$ for the TQ study group. The results revealed that A.a was statistically significantly sensitive to TQ rather than placebo gel (Table 4 and Graph 2).

\section{Discussion:}

Recently, the developing countries had been encouraged by the World Health Organization (WHO) to use natural remedies and traditional herbs for health care and disease treatment due to their minimal side effects and promising outcomes ${ }^{(18)}$.

NS and its active ingredient TQ has been used for the treatment of hypertension, cancer, rheumatoid arthritis, diabetes, bronchial asthma, hypertension, obesity, Behcet's disease, liver damage and other metabolic and autoimmune disorders ${ }^{(19)}$. TQ was found to be responsible for the therapeutic effect of $\mathrm{NS}^{(20)}$.

NS and TQ displayed abundant therapeutic properties on different oral diseases and conditions such as dental caries, intracanal medication, oral ulcerations, mucositis, wound healing, postextraction bone healing, oral cancer, gingival and periodontal diseases $^{(21)}$.

The potential role of TQ in periodontal regeneration is not fully defined yet. For treatment of periodontal diseases, TQ was administered locally to the periodontal pockets in the form of $0.1-0.2 \%$ TQ gel $^{(12,22)}$ and also in the form of fabricated periodontal chips containing $2.5 \mathrm{mg}$ of TQ ${ }^{(13)}$. In addition, periodontal diseases were treated with $0.2 \%$ TQ topical oral gel in conjunction with systemic administration of TQ in drinking water or systemic TQ administration only by gastric feeding ${ }^{(13,23)}$.

In our study, topical intrapocket $0.2 \%$ TQ gel was administered because topical application ensures that medication are delivered to the intended site of action with proper concentration and lasts for a sufficient duration. This goes with the recommendations of Puri and Puri ${ }^{(24)}$ who preferred topical drug administration in the treatment of moderate to sever periodontitis to overcome the drawbacks of systemic drug administration such as increased potential for adverse effects like allergic/ anaphylactic reaction, superinfection, gastric disturbances, nausea, vomiting, etc.

The present study evaluated the topical application of $0.2 \%$ TQ gel as an adjunctive to SRP in subjects with localized stage III/IV grade C periodontitis to get the potential anti-inflammatory, antibacterial and antioxidant benefits of local TQ gel, and achieving the benefits of SRP by arresting the destruction of periodontal support through the removal of the pathogenic bacteria in the periodontal pocket. This is in accordance with Ravishankar et $\mathrm{al}^{(25)}$ who concluded that nonsurgical mechanical periodontal debridement using SRP has been established as the gold standard in treating periodontitis with probing depth reductions and attachment level gains but the removal of bacterial deposits was complicated by restricted access to tortuous, deep pockets, furcation areas, irregular surfaces, and also the procedure is vastly dependent on the clinician skills. Thus, local drug delivery is beneficial as an adjunctive to SRP with minimal systemic involvement, better patient compliance, minimal patient discomfort, and maximum release of the therapeutic agent for an extended period at a steady pharmacological level in inaccessible areas to SRP. 
The results of our study showed that the study group demonstrated a statistical significant reduction of PPD values and a significant gain in RAL when compared to the control group values 8 weeks after gel application, this could be attributed to the great regenerative accelerating potential of TQ mediators if administered adjunctively to periodontal therapy. As explained in the studies of Alimoradi et al. 2018, Radwan and Mohamed 2018 ${ }^{(26,27)}$ who reported that TQ could promote mesenchymal stem cell migration, immunomodulation, as well as self-renewal ability and "stemness" by influencing the associated gene expression in vivo and in vitro. In addition, other experiment observed the significantly increased therapeutic potential and healing ability of mesenchymal stem cells after administration of TQ to the damaged sites ${ }^{(28)}$. Upon comparing the reduction of MMP-8 levels detected in the GCF samples at the end of the present study period, there was statistical significant reduction of MMP-8 levels in the TQ group when compared to the placebo group. This could be attributed to the anti-inflammatory and antioxidant effect of TQ. The studies of Majdalawieh et al., Kassab et al. and Bargi et al. proven a noticeable anti-inflammatory effect of TQ by the reduction of nitric oxide (NO) levels via reduction of inducible nitric oxide synthase (iNOS) mRNA production by macrophages and suppression of proinflammatory cytokines as IL-6, IL-1b, TNF-c, IFN- $\alpha$ and PGE2, with an increase of the anti-inflammatory IL-10 ${ }^{(29-31)}$.

In addition, Alwafi et al. 2014 ${ }^{(22)}$ ise pepdisplayed the role of TQ on periodontal and gingival inflammation in rats treated with TQ in their drinking water or as an oral gel, the values of periodontal indices, inflammatory clinical parameters and histological inflammatory signs were lower in comparison to the control group. Another rat study on periodontitis by Ozdemir et al. $^{(23)}$ oncluded that TQ has a preventive and suppressive role in the initiation and progression of periodontal inflammation and alveolar bone resorption. Moreover, 2 clinical randomized trials ${ }^{(12,13)}$ evaluated the efficiency of topical intrapocket administration of TQ in chronic periodontitis patients. The first study evaluated the local application of $0.2 \%$ TQ gel, in adjunction with SRP, after 6 weeks a statistically significant decrease was detected in PPD and alkaline phosphatase levels in the GCF besides a gain in RAL in the TQ group in contrary to the control patients. The second study used intapocket $2.5 \mathrm{mg}$ TQ impregnated chips for the treatment of deep pockets in chronic periodontitis, the results displayed significant improvements in the clinical attachments and other clinical periodontal parameters in TQ treated patients.

The antioxidant effect of TQ was explained through the scavenging ability of various free radicals ${ }^{(30,32)}$. TQ employs a combined anti-inflammatory and anti-oxidant action due to its efficiency to suppress lipid peroxidation and eicosanoid generation, specifically, thromboxane $\mathrm{B}$ and leukotrienes $\mathrm{B} 4$, via inhibiting COX and LOX molecular pathways ${ }^{(33)}$.

Considering the anti-inflammatory and anti-oxidant properties of TQ, it may play a significant role to prevent the initiation and progression of periodontal disease as observed in the current study.

Regarding the Microbiological effect of the topical application of $0.2 \%$ TQ gel as an adjunctive to SRP on count of A.a in the collected subgingival plaque samples, A.a was found to be statistically significantly sensitive to $0.2 \%$ TQ gel rather than placebo gel. One of the suggested mechanisms was the weakening effect of TQ on the integrity of bacterial membranes through pump efflux inhibition, also TQ plays an important role in decreasing the bacterial resistance ${ }^{(34,35)}$.

Moreover, Goel and Mishra in 2018 suggested that the probable mechanism of action of TQ against bacterial cells was due to the production of reactive oxygen species. ${ }^{(36)}$. 
ISSN 2515-8260 Volume 05, Issue 01, 2018

The microbiological assessment in our study is also in agreement with studies performed by Kapil et al. and Alwafi et al. ${ }^{(12,22)}$ who reported that Porphyromonas gingivalis, A. actinomycetemcomitans and Prevotella intermedia was observed in these studies to be sensitive to topical TQ administration and TQ could significantly reduce the number of subgingival bacteria.

In addition, the antimicrobial activities of $N S$ were tested against microbial strains isolated from the oral cavities of periodontitis patients including Staphylococcus epidermidis, Staphylococcus aureus, Streptococcus pneumoniae, Enterococcus faecalis, Klebsiella pneumoniae, Proteus sp., Acinetobacter baumanniil calcoaceticus, Porphyromonas sp. and Veillonella sp.. The microbial analysis displayed high antibacterial activities of the essential oil extract of $N S$ against all the observed species.

\section{Conclusion:}

Analogous to the reported previous outcomes, the TQ -treated group of our clinical study also presented a significant improvement in all clinical and biochemical parameters in localized stage III/IV grade $\mathrm{C}$ periodontitis including PPD, RAL, along with the of MMP-8 inflammatory levels in the GCF and the A.a sensitivity in subgingival plaque samples compared to the non-TQ-treated patients.

\section{References:}

1. Caton JG, Armitage G, Berglundh T, Chapple ILC, Jepsen S, Kornman KS, Mealey BL, Papapanou PN, Sanz M, Tonetti MS. A new classification scheme for periodontal and peri-implant diseases and conditions - Introduction and key changes from the 1999 classification. J Periodontol. 2018 Jun;89 Suppl 1:S1-S8. doi: 10.1002/JPER.18-0157. PMID: 29926946.

2. Oppermann RV, Haas AN, Rösing CK, Susin C. Epidemiology of periodontal diseases in adults from Latin America. Periodontol 2000. 2015 Feb;67(1):13-33. doi: 10.1111/prd.12061. PMID: 25494596.

3. Miller K, Treloar T, Guelmann M, Rody WJ Jr, Shaddox LM. Clinical Characteristics of Localized Aggressive Periodontitis in Primary Dentition. J Clin Pediatr Dent. 2018;42(2):95-102. doi: 10.17796/1053-4628-42.2.3. Epub 2017 Oct 31. PMID: 29087795; PMCID: PMC5906128.

4. Burgess DK, Huang H, Harrison P, Kompotiati T, Aukhil I, Shaddox LM. NonSurgical Therapy Reduces Presence of JP2 Clone in Localized Aggressive Periodontitis. J Periodontol. 2017 Dec;88(12):1263-1270. doi: 10.1902/jop.2017.170285. Epub 2017 Aug 18. PMID: 28820321; PMCID: PMC5700858.

5. Singh N, Chandel S, Singh H, Agrawal A, Savitha AN. Effect of scaling \& root planing on the activity of ALP in GCF \& serum of patients with gingivitis, chronic and aggressive periodontitis: A comparative study. J Oral Biol Craniofac Res. 2017 May-Aug;7(2):123-126. doi: 10.1016/i.jobcr.2017.03.006. Epub 2017 Mar 27. PMID: 28706787; PMCID: PMC5497333.

6. da Costa LFNP, Amaral CDSF, Barbirato DDS, Leão ATT, Fogacci MF. Chlorhexidine mouthwash as an adjunct to mechanical therapy in chronic periodontitis: A meta-analysis. J Am Dent Assoc. 2017 May;148(5):308-318. doi: 10.1016/i.adaj.2017.01.021. Epub 2017 Mar 9. PMID: 28284417.

7. Al-Shammari NM, Shafshak SM, Ali MS. Effect of $0.8 \%$ Hyaluronic Acid in Conventional Treatment of Moderate to Severe Chronic Periodontitis. J Contemp Dent Pract. 2018 May 1;19(5):527-534. PMID: 29807962 
8. Abdollahzadeh Sh, Mashouf R, Mortazavi H, Moghaddam M, Roozbahani N, Vahedi M. Antibacterial and antifungal activities of punica granatum peel extracts against oral pathogens. J Dent (Tehran). 2011 Winter;8(1):1-6. Epub 2011 Mar 31. PMID: 21998800; PMCID: PMC3184731.

9. Abdelrazek HMA, Kilany OE, Muhammad MAA, Tag HM, Abdelazim AM. Black Seed Thymoquinone Improved Insulin Secretion, Hepatic Glycogen Storage, and Oxidative Stress in Streptozotocin-Induced Diabetic Male Wistar Rats. Oxid Med Cell Longev. 2018 Mar 4;2018:8104165. doi: 10.1155/2018/8104165. PMID: 29686746; PMCID: PMC5857299.

10. Farkhondeh T, Samarghandian S, Borji A. An overview on cardioprotective and anti-diabetic effects of thymoquinone. Asian Pac J Trop Med. 2017 Sep;10(9):849854. doi: 10.1016/j.apitm.2017.08.020. Epub 2017 Oct 9. PMID: 29080612.

11. Gholamnezhad Z, Havakhah S, Boskabady MH. Preclinical and clinical effects of Nigella sativa and its constituent, thymoquinone: A review. J Ethnopharmacol. 2016 Aug 22;190:372-86. doi: 10.1016/j.jep.2016.06.061. Epub 2016 Jun 27. PMID: 27364039.

12. Kapil H, Suresh DK, Bathla SC, Arora KS. Assessment of clinical efficacy of locally delivered $0.2 \%$ Thymoquinone gel in the treatment of periodontitis. Saudi Dent J. 2018 Oct;30(4):348-354. doi: 10.1016/j.sdentj.2018.06.001. Epub 2018 Jun 11. PMID: 30202173; PMCID: PMC6128318.

13. Al-Bayaty, F.H.; Kamaruddin, A.A.; Ismail, M.A.; Abdulla, M.A. Formulation and Evaluation of a New Biodegradable Periodontal Chip Containing Thymoquinone in a Chitosan Base for the Management of Chronic Periodontitis. J. Nanomater. 2013, 2013, 397308.

14. Papapanou PN, Sanz M, Buduneli N, Dietrich T, Feres M, Fine DH, Flemmig TF, Garcia R, Giannobile WV, Graziani F, Greenwell H, Herrera D, Kao RT, Kebschull M, Kinane DF, Kirkwood KL, Kocher T, Kornman KS, Kumar PS, Loos BG, Machtei E, Meng H, Mombelli A, Needleman I, Offenbacher S, Seymour GJ, Teles R, Tonetti MS. Periodontitis: Consensus report of workgroup 2 of the 2017 World Workshop on the Classification of Periodontal and Peri-Implant Diseases and Conditions. J Clin Periodontol. 2018 Jun;45 Suppl 20:S162-S170. doi: 10.1111/jcpe.12946. PMID: 29926490.

15. Guentsch A, Jentsch H, Pfister W, Hoffmann T, Eick S. Moxifloxacin as an adjunctive antibiotic in the treatment of severe chronic periodontitis. J Periodontol. 2008 Oct;79(10):1894-903. doi: 10.1902/jop.2008.070493. PMID: 18834244.

16. Clark DC, Chin Quee T, Bergeron MJ, Chan EC, Lautar-Lemay C, de Gruchy K. Reliability of attachment level measurements using the cementoenamel junction and a plastic stent. J Periodontol. 1987 Feb;58(2):115-8. doi: 10.1902/jop.1987.58.2.115. PMID: 3469400.

17. Kunjappu JJ, Mathew VB, Hegde S, Kashyap R, Hosadurga R. Assessment of the alkaline phosphatase level in gingival crevicular fluid, as a biomarker to evaluate the effect of scaling and root planing on chronic periodontitis: An in vivo study. J Oral Maxillofac Pathol. 2012 Jan;16(1):54-7. doi: 10.4103/0973-029X.92974. PMID: 22438644; PMCID: PMC3303524.

18. Chen AD, Wang CL, Qin Y, Tian L, Chen LB, Yuan XM, Ma LX, Wang YF, Sun JR, Wang HS, Dai N; DOLPHIN investigator group. The effect of Danshen extract on lipoprotein-associated phospholipase $\mathrm{A}_{2}$ levels in patients with stable angina pectoris: study protocol for a randomized controlled trial - the DOLPHIN study. Trials. 2017 Dec 20;18(1):606. doi: 10.1186/s13063-017-2336-2. PMID: 29262859 ; PMCID: PMC5738193. 
ISSN 2515-8260 Volume 05, Issue 01, 2018

19. Namazi N, Larijani B, Ayati MH, Abdollahi M. The effects of Nigella sativa L. on obesity: A systematic review and meta-analysis. J Ethnopharmacol. 2018 Jun 12;219:173-181. doi: 10.1016/j.jep.2018.03.001. Epub 2018 Mar 17. PMID: 29559374.

20. Majdalawieh AF, Fayyad MW, Nasrallah GK. Anti-cancer properties and mechanisms of action of thymoquinone, the major active ingredient of Nigella sativa. Crit Rev Food Sci Nutr. 2017 Dec 12;57(18):3911-3928. doi: 10.1080/10408398.2016.1277971. PMID: 28140613.

21. Al-Attass SA, Zahran FM, Turkistany SA. Nigella sativa and its active constituent thymoquinone in oral health. Saudi Med J. 2016 Mar;37(3):235-44. doi: 10.15537/smj.2016.3.13006. PMID: 26905343; PMCID: PMC4800885.

22. Alwafi, H. Benefits of Thymoquinone, a Nigella Sativa Extract in Preventing Dental Caries Initiation and University, Medford, MA, USA, 2014.

23. Ozdemir H, Kara MI, Erciyas K, Ozer H, Ay S. Preventive effects of thymoquinone in a rat periodontitis model: a morphometric and histopathological study. J Periodontal Res. 2012 Feb;47(1):74-80. doi: 10.1111/j.16000765.2011.01406.x. Epub 2011 Oct 13. PMID: 21992581.

24. Surê. Puri K, Puri N. Local drug delivery agents as adjuncts to endodontic and periodontal therapy. J Med Life. 2013;6(4):414-9. Epub 2013 Dec 25. PMID: 24868252; PMCID: PMC4034307.

25. Ravishankar PL, Kumar YP, Anila EN, Chakraborty P, Malakar M, Mahalakshmi R. Effect of local application of curcumin and ornidazole gel in chronic periodontitis patients. Int $\mathrm{J}$ Pharm Investig. 2017 Oct-Dec;7(4):188-192. doi: 10.4103/jphi.JPHI_82_17. PMID: 29692978; PMCID: PMC5903023.

26. Alimoradi E, Sisakhtnezhad S, Akrami H. Thymoquinone influences the expression of genes involved in self-renewal and immunomodulatory potential of mouse bone marrow-derived mesenchymal stem cells in vitro. Environ Toxicol Pharmacol. 2018 Jun;60:216-224. doi: 10.1016/j.etap.2018.05.001. Epub 2018 May 7. PMID: 29763882.

27. Radwan RR, Mohamed HA. Nigella sativa oil modulates the therapeutic efficacy of mesenchymal stem cells against liver injury in irradiated rats. J Photochem Photobiol B. 2018 Jan;178:447-456. doi: 10.1016/j.jphotobiol.2017.11.037. Epub 2017 Dec 2. PMID: 29216568.

28. Arslan, A.H.; Tomruk, C.Ö.; Meydanll, E.G.; Özdemir, I :; Duygu Çapar, G.; Kütan, E.; Yllmaz, A.; Yalçın Ülker, G.M. Histopathological evaluation of the effect of systemic thymoquinone administration on healing of bone defects in rat tibia. Biotechnol. Biotechnol. Equip. 2017, 31, 175-181.

29. Majdalawieh AF, Fayyad MW. Immunomodulatory and anti-inflammatory action of Nigella sativa and thymoquinone: A comprehensive review. Int Immunopharmacol. 2015 Sep;28(1):295-304. doi: 10.1016/j.intimp.2015.06.023. Epub 2015 Jun 26. PMID: 26117430.

30. Kassab, R.B.; El-Hennamy, R.E. The role of thymoquinone as a potent antioxidant in ameliorating the neurotoxic effect of sodium arsenate in female rat. Egypt. J. Basic Appl. Sci. 2017, 4, 160-167. i[s]

31. Bargi, R.; Asgharzadeh, F.; Beheshti, F.; Hosseini, M.; Sadeghnia, H.R.; Khazaei, M. The effects of thymoquinone on hippocampal cytokine level, brain oxidative stress status and memory deficits induced by lipopolysaccharide in rats. Cytokine 2017, 96, 173-184.

32. Nader, M.A.; el-Agamy, D.S.; Suddek, G.M. Protective effects of propolis and 
ISSN 2515-8260 Volume 05, Issue 01, 2018

thymoquinone on development of atherosclerosis in cholesterol-fed rabbits. Arch. Pharm. Res. 2010, 33, 637-643. istep]

33. Mostofa, A.G.M.; Hossain, M.K.; Basak, D.; Bin Sayeed, M.S. Thymoquinone as a Potential Adjuvant Therapy for Cancer Treatment: Evidence from Preclinical

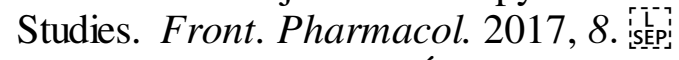

34. Mouwakeh A, Telbisz Á, Spengler G, Mohácsi-Farkas C, Kiskó G. Antibacterial and Resistance Modifying Activities of Nigella sativa Essential Oil and its Active Compounds Against Listeria monocytogenes. In Vivo. 2018 Jul-Aug;32(4):737743. doi: 10.21873/invivo.11302. PMID: 29936453; PMCID: PMC6117775.

35. Kouidhi B, Zmantar T, Jrah H, Souiden Y, Chaieb K, Mahdouani K, Bakhrouf A. Antibacterial and resistance-modifying activities of thymoquinone against oral pathogens. Ann Clin Microbiol Antimicrob. 2011 Jun 27;10:29. doi: 10.1186/1476-0711-10-29. PMID: 21707998; PMCID: PMC3146813.

36. Goel S, Mishra P. Thymoquinone inhibits biofilm formation and has selective antibacterial activity due to ROS generation. Appl Microbiol Biotechnol. 2018 Feb;102(4):1955-1967. doi: 10.1007/s00253-018-8736-8. Epub 2018 Jan 22. PMID: 29356869.

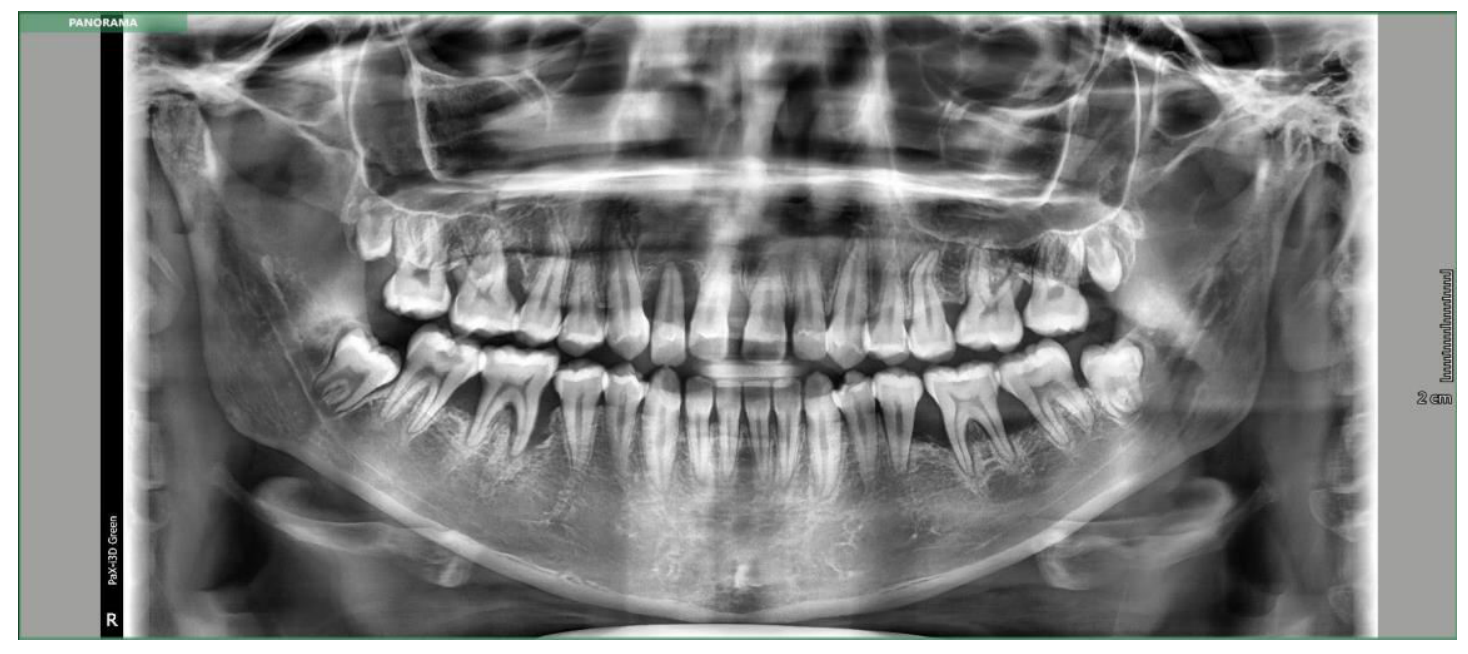

Fig. 1: preoperative panoramic x-ray.

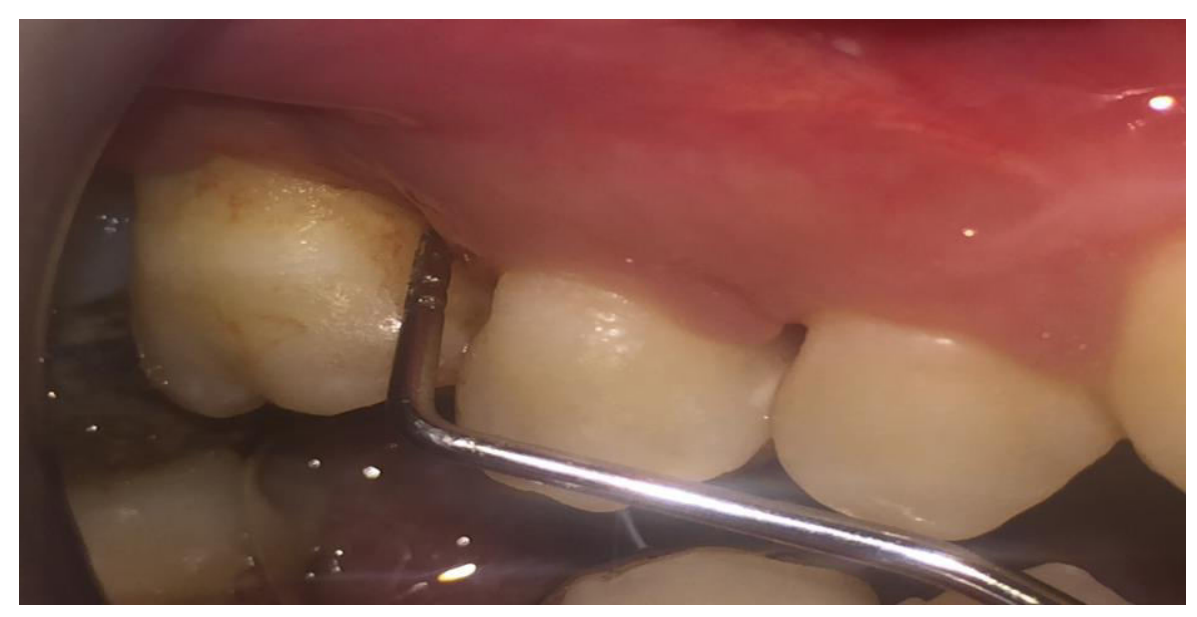

Fig. 2: preoperative PPD (Study group). 
European Journal of Molecular \& Clinical Medicine

ISSN 2515-8260 Volume 05, Issue 01, 2018

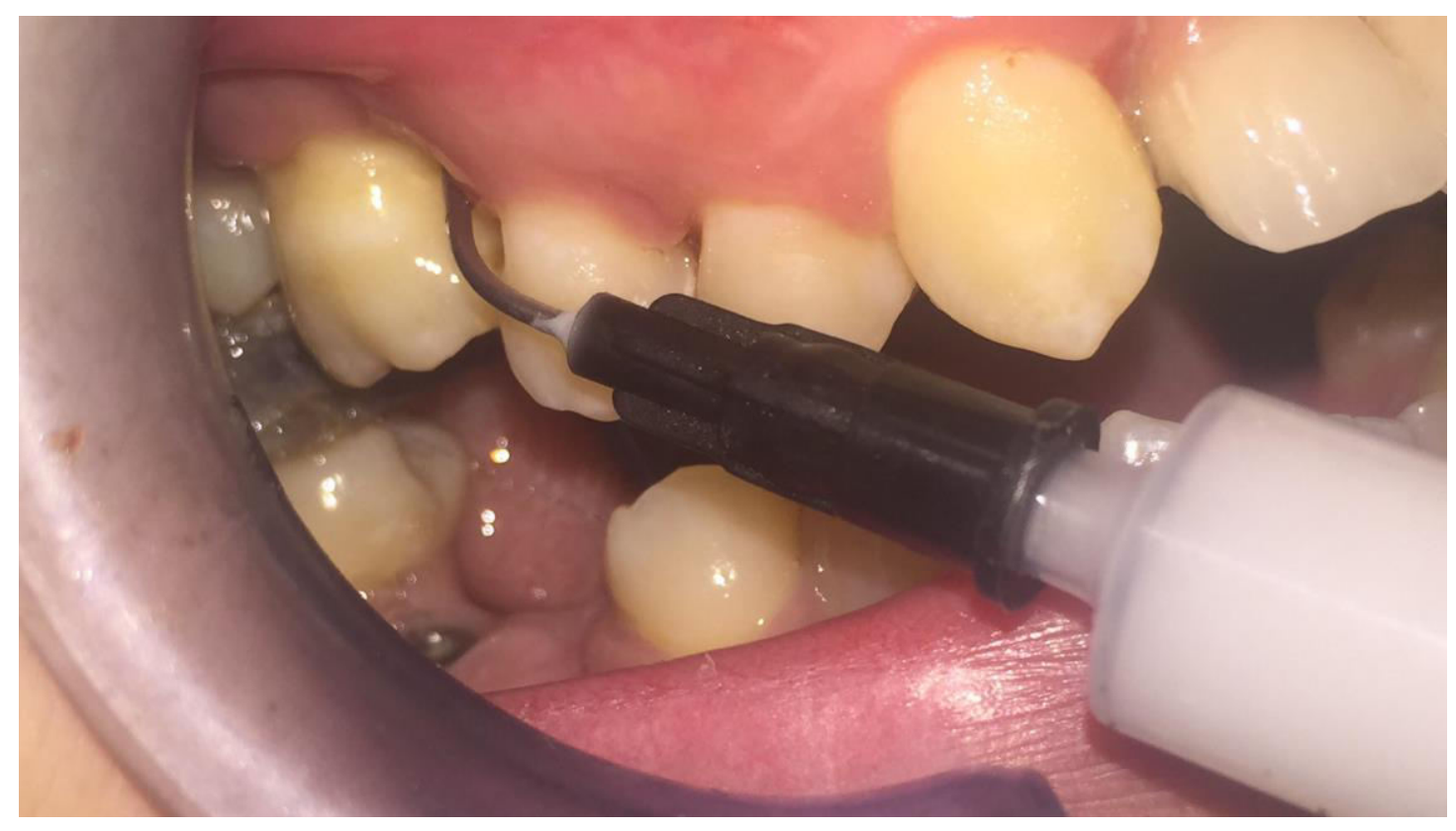

Fig. 3: Topical application of $0.2 \%$ Thymoquinone gel.

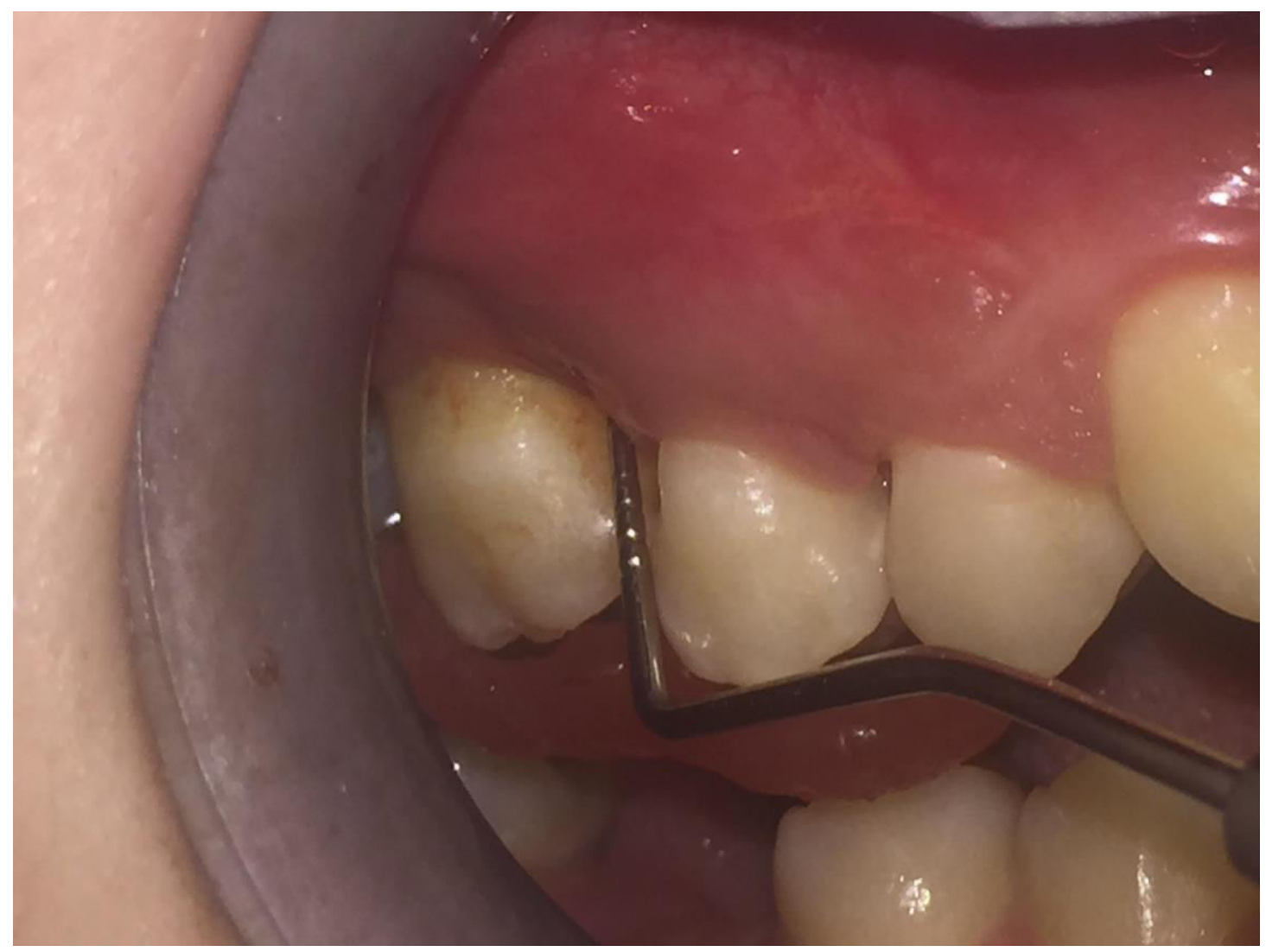

Fig. 2: Post-operative PPD (Study group). 
European Journal of Molecular \& Clinical Medicine

ISSN 2515-8260 Volume 05, Issue 01, 2018

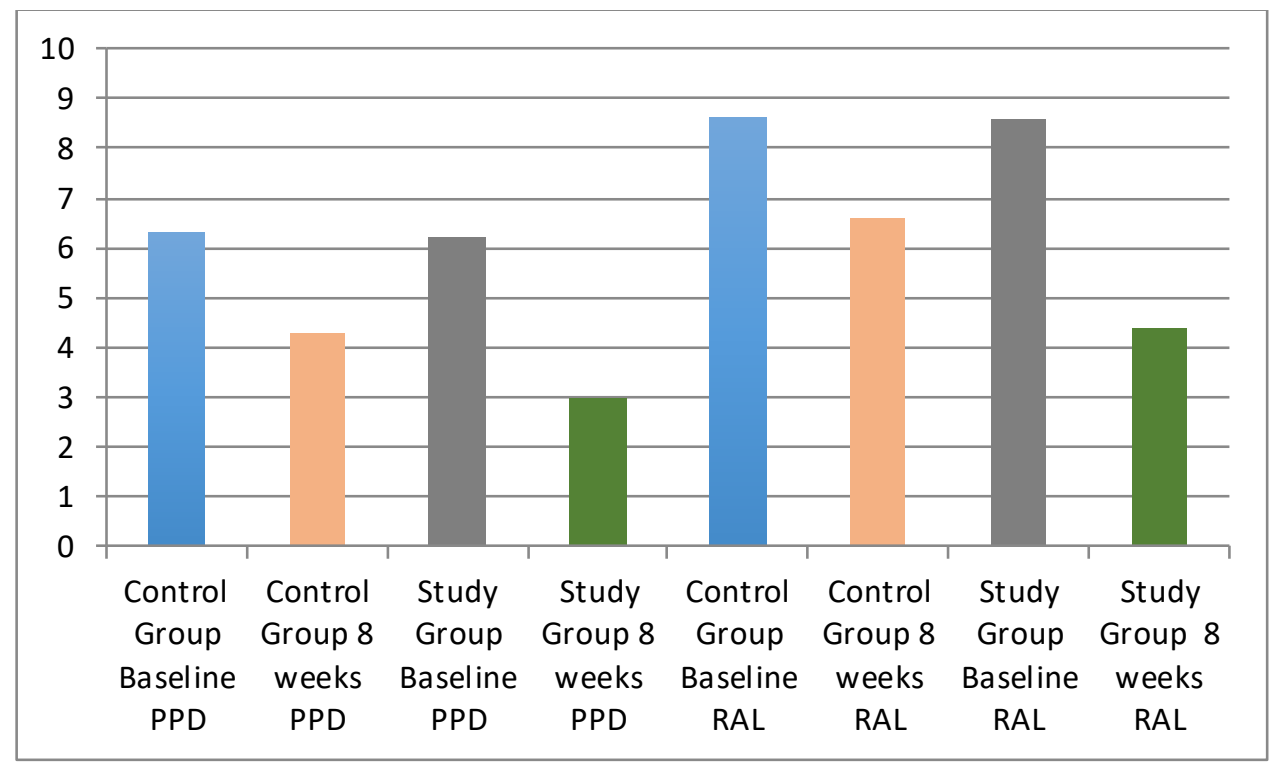

Graph 1: Mean PPD and RAL at baseline and 8 weeks postoperatively.

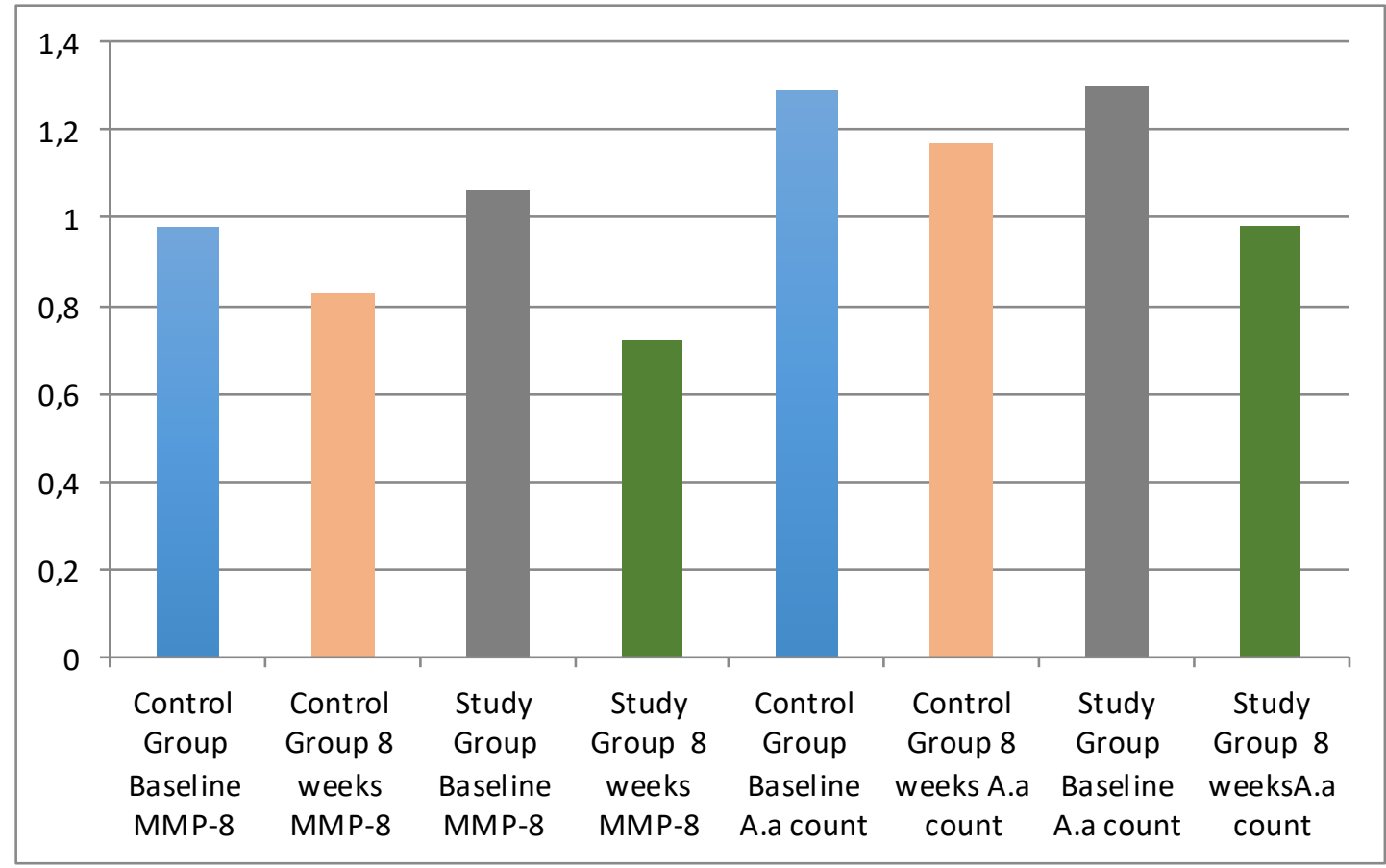

Graph 2: Mean MMP-2 values and A.a count at baseline and 8 weeks postoperatively. 
ISSN 2515-8260 Volume 05, Issue 01, 2018

Table 1: Mean PPD at baseline and 8 weeks postoperatively.

\begin{tabular}{|c|c|c|c|c|}
\hline \multirow[b]{2}{*}{ Test period } & \multicolumn{2}{|c|}{ Mean PPD } & \multirow[b]{2}{*}{$\begin{array}{c}\text { Independent Samples } \\
\text { Test }\end{array}$} & \multirow[b]{2}{*}{ p-value } \\
\hline & $\begin{array}{l}\text { Control } \\
\text { Group } \\
\mathrm{X} \pm \mathrm{SD}\end{array}$ & $\begin{array}{c}\text { Study Group } \\
\mathrm{X} \pm \mathrm{SD}\end{array}$ & & \\
\hline Baseline & $6.3 \pm 0.91$ & $6.23 \pm 0.93$ & Sig. $(2$-tailed $)=0.00^{*}$ & $\mathrm{p}<0.05^{*}$ \\
\hline 8 weeks & $4.3 \pm 0.91$ & $2.97 \pm 0.61$ & Sig. $(2$-tailed $)=0.00^{*}$ & $\mathrm{p}<0.05^{*}$ \\
\hline \multirow[b]{2}{*}{$\begin{array}{l}\text { Wilcoxon Signed } \\
\text { Ranks Test }\end{array}$} & $Z=-5.47$ & $Z=-4.87$ & & \\
\hline & $\begin{array}{c}\text { Asymp. Sig. (2- } \\
\text { tailed) }=0.00 * \\
\text { p }<0.05\end{array}$ & $\begin{array}{c}\text { Asymp. Sig. (2- } \\
\text { tailed) }=0.00^{*} \\
\text { p }<0.05\end{array}$ & & \\
\hline
\end{tabular}

$\mathrm{X} \pm \mathrm{SD} \quad$ : Mean \pm Standard deviation

* $\quad$ :Statistical significant difference

Table 2: Mean RAL at baseline and 8 weeks postoperatively.

\begin{tabular}{|c|c|c|c|c|}
\hline \multirow[b]{2}{*}{ Test period } & \multicolumn{2}{|c|}{ Mean PPD } & \multirow[b]{2}{*}{$\begin{array}{c}\text { Independent Samples } \\
\text { Test }\end{array}$} & \multirow[b]{2}{*}{ p-value } \\
\hline & $\begin{array}{l}\text { Control } \\
\text { Group } \\
\mathrm{X} \pm \mathrm{SD}\end{array}$ & $\begin{array}{c}\text { Study Group } \\
\mathrm{X} \pm \mathrm{SD}\end{array}$ & & \\
\hline Baseline & $6.3 \pm 0.91$ & $6.23 \pm 0.93$ & Sig. $($ 2-tailed $)=0.00 *$ & $\mathrm{p}<0.05^{*}$ \\
\hline 8 weeks & $4.3 \pm 0.91$ & $2.97 \pm 0.61$ & Sig. $(2$-tailed $)=0.00 *$ & $\mathrm{p}<0.05^{*}$ \\
\hline \multirow[b]{2}{*}{$\begin{array}{l}\text { Wilcoxon Signed } \\
\text { Ranks Test }\end{array}$} & $Z=-5.39$ & $Z=-5.06$ & & \\
\hline & $\begin{array}{c}\text { Asymp. Sig. (2- } \\
\text { tailed) }=0.00^{*} \\
\text { p }<0.05\end{array}$ & $\begin{array}{c}\text { Asymp. Sig. }(2- \\
\text { tailed) }=0.00^{*} \\
\text { p }<0.05\end{array}$ & & \\
\hline
\end{tabular}

$\mathrm{X} \pm \mathrm{SD} \quad:$ Mean \pm Standard deviation

* $\quad$ :Statistical significant difference

Table 3: Mean MMP-8 at baseline and 8 weeks postoperatively.

\begin{tabular}{|c|c|c|c|c|}
\hline \multirow[b]{2}{*}{ Test period } & \multicolumn{2}{|c|}{ Mean PPD } & \multirow[b]{2}{*}{$\begin{array}{c}\text { Independent Samples } \\
\text { Test }\end{array}$} & \multirow[b]{2}{*}{$\mathrm{p}$-value } \\
\hline & $\begin{array}{l}\text { Control } \\
\text { Group } \\
\mathrm{X} \pm \mathrm{SD}\end{array}$ & $\begin{array}{c}\text { Study Group } \\
\mathrm{X} \pm \mathrm{SD}\end{array}$ & & \\
\hline Baseline & $0.98 \pm 0.26$ & $1.06 \pm 0.30$ & Sig. (2-tailed $)=0.00^{*}$ & $\mathrm{p}<0.05^{*}$ \\
\hline 8 weeks & $0.83 \pm 0.20$ & $0.72 \pm 0.25$ & Sig. $(2$-tailed $)=0.00^{*}$ & $\mathrm{p}<0.05^{*}$ \\
\hline \multirow[b]{2}{*}{ Paired t-test } & $t=9.12$ & $\mathrm{t}=27.57$ & & \\
\hline & $\begin{array}{c}\text { Sig. }(2 \text {-tailed })= \\
0.00 * \\
\text { p }<0.05\end{array}$ & $\begin{array}{c}\text { Sig. }(2 \text {-tailed })= \\
0.00 * \\
\text { p }<0.05\end{array}$ & & \\
\hline
\end{tabular}

$\mathrm{X} \pm \mathrm{SD} \quad$ : Mean \pm Standard deviation

* $\quad$ :Statistical significant difference

Table 4: Mean A.a count at baseline and 8 weeks postoperatively.

\begin{tabular}{|c|c|c|c|c|}
\hline \multirow[b]{2}{*}{ Test period } & \multicolumn{2}{|c|}{ Mean PPD } & \multirow[b]{2}{*}{$\begin{array}{c}\text { Independent Samples } \\
\text { Test }\end{array}$} & \multirow[b]{2}{*}{ p-value } \\
\hline & $\begin{array}{l}\text { Control } \\
\text { Group } \\
\mathrm{X} \pm \mathrm{SD}\end{array}$ & $\begin{array}{c}\text { Study Group } \\
\mathrm{X} \pm \mathrm{SD}\end{array}$ & & \\
\hline Baseline & $1.29 \pm 0.20$ & $1.30 \pm 0.19$ & Sig. $(2$-tailed $)=0.00^{*}$ & $\mathrm{p}<0.05^{*}$ \\
\hline 8 weeks & $1.17 \pm 0.20$ & $0.98 \pm 0.19$ & Sig. $(2$-tailed $)=0.00^{*}$ & $\mathrm{p}<0.05^{*}$ \\
\hline \multirow[b]{2}{*}{ Paired t-test } & $t=16.85$ & $t=36.19$ & & \\
\hline & $\begin{array}{c}\text { Sig. }(2-\text { tailed })= \\
0.00^{*} \\
\text { p }<0.05\end{array}$ & $\begin{array}{c}\text { Sig. }(2 \text {-tailed })= \\
0.00 * \\
\text { p }<0.05\end{array}$ & & \\
\hline $\begin{array}{l}: \mathrm{M} \\
: \mathrm{St}\end{array}$ & $\begin{array}{l}\text { ndard de } \\
\text { ignifican }\end{array}$ & $\begin{array}{l}\text { on } \\
\text { ference }\end{array}$ & & \\
\hline
\end{tabular}

